\title{
GRAMÁTICA E ENSINO: PRESSUPOSTOS TEÓRICOS E METODOLÓGICOS
}

\author{
Ana Zandwais
}

RESUMO: This paper presents some results of research developed in the Project "Grammar and Teaching". The purpose of this article is to analyse the main linguistic trends that sustain pratices of teaching adopted by: a) teachers of Portuguese at public schools in Porto Alegre city; b) instructional materials often used by these teachers. The results of a preliminar investigation show several gaps between the theoretical and practical fields.

PALAVRAS-CHAVE: pressupostos teóricos, práticas de ensino, livros didáticos, componentes da língua.

\section{INTRODUÇÃO}

O Projeto "Gramática e Ensino", implantado junto ao Curso de graduação do Instituto de Letras da UFRGS, desde outubro de 1994, tem como metas fundamentais: a) estreitar relações entre o processo de formação de docentes pela Universidade e o universo de referências teórico-práticas que caracterizam a realidade de ensino de língua portuguesa em escolas públicas de $1^{\circ}$ grau; b) acompanhar relatos de práticas docentes desenvolvidas nas escolas, com vistas ao resgate de concepções lingüísticas que alicerçam as práticas; c) analisar os tipos de pressupostos teóricos e os componentes da língua ${ }^{1}$ mobilizados, com maior ênfase, em livros didáticos de boa circulação entre as escolas.

O Projeto conta, atualmente, com alunos-bolsistas da disciplina LET437 (Semântica Frasal e Textual) e colaboradores do Curso de Pós-Graduação na área de Estudos da Linguagem que, em conjunto, têm centrado seus interesses em investigar: (1) como professores e livros didáticos exploram o funcionamento do componente semântico em suas propostas de ensino; (2) que tipos de relações são, via de regra, estabelecidas entre os componentes morfológico, sintático e semântico da língua; (3) quais os tipos de componentes predominantes nas práticas pedagógicas e os níveis de exploração desses componentes, em diferentes séries do $1^{\circ}$ grau.

\section{Metodologia}

Ana Zandwais é professora do Instituto de Letras da UFRGS.

${ }^{1}$ Referimo-nos, acima, aos componentes morfológico, sintático, semântico e pragmático. 
A fim de podermos sistematizar os dados que responderiam aos questionamentos propostos, dividimos a pesquisa em duas etapas distintas e intercomplementares. A primeira consistiu de sessões de estudos semanais com docentes de duas escolas da rede municipal de ensino de Porto Alegre (EMs. Aramy Silva e Victor Issler), das quais participaram alunosestagiários, bolsistas e docentes da UFRGS. Nessa etapa, foram registrados, através de gravações de diálogos ${ }^{2}$, os tipos de articulações que os professores conseguiram estabelecer entre as práticas docentes, construídas para agilizar suas propostas de ensino, e os referenciais teóricos apontados como norteadores das propostas.

Já na segunda etapa, dois bolsistas do Projeto passaram a reunir-se semanalmente conosco, tendo como tarefas iniciais realizar escutas dos trabalhos desenvolvidos nas escolas e selecionar livros didáticos de $1^{\circ}$ grau, tomando o cuidado de não somente selecionar livros mencionados pelos professores, mas também de diversificá-los, de acordo com a variedade de pressupostos apresentados como norteadores das práticas durante as sessões de estudo.

Como ponto de partida para essa segunda etapa, então, foram selecionados cinco livros didáticos, de acordo com os seguintes critérios: a) três livros apresentaram em comum os fatos de terem sido mencionados, e de apresentarem pressupostos de língua como instrumento de comunicação ${ }^{3}$; b) dois livros caracterizaram-se por terem sido elaborados a partir de pressupostos da Lingüística Textual e de Teorias Genéticas do Conhecimento (Construtivistas), sendo tais pressupostos configurados, pelos professores, como norteadores das práticas de ensino.

\section{Processos de interface com escolas e investigação}

Na primeira escola - E.M. Victor Issler - fomos alvos dos seguintes questionamentos: $A$ universidade possui algum acúmulo de conhecimentos dos tipos de propostas pedagógicas que decorrem de referenciais construtivistas?; Se o objetivo do projeto é propor um processo de interface com o ensino básico, gostaríamos de saber quais as referências que temos em comum, além de uma formação específica.

Nesta escola, as sessões de estudo, desenvolvidas ao longo de seis meses, permitiramnos observar realidades tais como: (a) presença constante e interesse dos Serviços de Orientação e Supervisão por discussões realizadas com os docentes de língua materna;(b) construção de políticas pedagógicas comuns a todas as áreas de ensino; (c) existência de projetos de natureza interdisciplinar; (d) formulação de propostas de ensino embasadas em referenciais construtivistas, como formação de grupos áulicos, avaliações realizadas no decorrer de cada aula, acompanhamento permanente e discussões a respeito do processo de aprendizagem das turmas. Entretanto, contraditoriamente às nossas expectativas, não avançamos em discussões sobre modos de produção de campos conceituais em língua portuguesa.

Na segunda escola - E.M. Aramy Silva - os professores, face as nossas solicitações de que debatessem, com a equipe, as propostas teóricas que alicerçavam seus programas de

\footnotetext{
2 Os diálogos, a que nos referimos acima, consistiram de escutas de exposições feitas por docentes, questionamentos nossos e de algumas intervenções atendendo a questões também formuladas pelos expositores.

3 Os argumentos utilizados para o exame de três livros com pressupostos teóricos comuns recaíram sobre possibilidades de comparação entre práticas de ensino-aprendizagem, modos de mobilizar os componentes da língua e de interpretar a função comunicativa, a partir das práticas.
} 
ensino, relacionando-as com práticas de sala de aula, sugeriram a utilização de materiais pedagógicos elaborados pelo próprio corpo docente, a fim de que as possibilidades de problematizações emergentes dos diálogos fossem sustentadas por realidades vivenciadas em seu cotidiano escolar.

Assim, atendendo a solicitações dos professores, principiamos por análises de programas de ensino, que foram ilustrados com discussões de práticas de análise e de produção de textos desenvolvidas em sala de aula.

A informação inicial que recebemos foi de que os princípios teóricos adotados encontram sustentação em fundamentos da Lingüística Textual. Desse modo, durante o processo de escuta, procuramos relacionar os relatos dos professores com os seguintes procedimentos colocados em evidência: a) articular conteúdos morfossintáticos com diferentes tipos de textos; b) privilegiar os domínios temáticos e o modo de construção dos textos em relação aos aspectos formais dos mesmos (concordância, regência, acentuação); c) oportunizar operações de reescrita de textos, a fim de instaurar situações de reflexão sobre as condições em que estes podem tornar-se mais legíveis para o leitor.

À medida, porém, que os relatos iam sendo realizados, constatamos, através de escutas e discussões posteriores, que, enquanto algumas intervenções ${ }^{4}$ dos professores, reportando-se a questionamentos dos alunos, perseguiam os princípios adotados, outras não poderiam sustentarse pelos mesmos parâmetros.

Com o objetivo de tornar mais explícitas nossas observações, passaremos a relatar dois processos de interface, a partir dos quais analisamos relações teórico-práticas.

2.1. Relato de prática pedagógica envolvendo leitura e análise do funcionamento de textos instrucionais (E.M. Aramy Silva)

Tomando como referência básica um conjunto de textos instrucionais previamente selecionados (manuais de instrução e bulas farmacêuticas), um professor de $8^{\mathrm{a}}$ série propôs-se a debater, com os alunos, a respeito dos tipos de relações de intersubjetividade presentes nos textos. Após concluir, com a classe, que tais textos apresentavam uma prática de ensino diretiva, objetiva, cuja finalidade consistia em dirigir as ações dos leitores, o professor passou a destacar a regularidade de emprego do modo imperativo nos textos, observando que este modo verbal seria o mais adequado à função de direcionar a leitura, sem proporcionar, aos leitores, dúvidas ou insegurança.

Observou, também, por outro lado, que, em muitos casos, a substituição do modo imperativo pelo infinitivo justificava-se como uma tentativa de atenuar relações hierárquicas entre o produtor e o leitor. Deste modo, ao analisarem enunciados como "Tome duas drágeas ao dia"; "Manter em lugar seco e fresco" (textos em anexo), estes foram considerados apropriados para textos instrucionais. Entretanto, um dos textos escolhidos apresentou um tipo de construção desconhecida, na medida em que substituiu o emprego do modo imperativo por verbos modais e não por formas de infinitivo, como os alunos esperavam. Portanto, enunciados do tipo: "As gotas podem ser administradas diretamente na boca ou diluídas num pouco d'água"...; "Uma dieta leve e o uso de sedativos podem ser de valor como coadjuvantes do tratamento"; "As doses poderão ser aumentadas a critério médico"; foram considerados

\footnotetext{
${ }^{4}$ Qualificamos como intervenções, os comentários que emergiram da avaliação dos processos de ensino-aprendizagem.
} 
impróprios para o texto e estranhos para os alunos, o que gerou polêmica, na medida em que, ao ser questionado, o professor não conseguiu produzir uma explicação que lhes satisfizesse.

Apresentando, então, o relato, o professor transferiu a questão para o grupo, o que permitiu que discutíssemos a respeito de modalizadores textuais, focalizando, como pontos centrais de nossa abordagem, os efeitos de sentidos produzidos pelos modais poder e dever, em diferentes circunstâncias de interlocução (possibilidades, probabilidades, pedidos, permissões, obrigações, advertências, ordens, conselhos), resgatando, assim, relações de assimetria entre os domínios da forma e do sentido na linguagem.

\subsection{Relato de prática pedagógica envolvendo avaliação de textos narrativos}

A partir de produções narrativas sobre o tema vida de estudante, as quais deveriam conter, no desenvolvimento do texto, descrições com função avaliativa, uma professora de $6^{a}$ série propôs-se a relatar os resultados de uma análise provisória da qualidade dos textos produzidos pelos alunos.

Indagada a respeito dos critérios que tornariam determinados textos mais qualitativos do que outros, a professora observou que, de acordo com a proposta e discussões realizadas em aula, consideraria bons textos: a) os que apresentassem uma narrativa em $3^{\mathrm{a}}$ pessoa, envolvendo fatos relacionados à vida de um personagem real ou imaginário; b) aqueles que contivessem diferentes tipos de avaliação sobre comportamentos, valores, costumes de estudante, de modo que a inscrição de avaliações no texto narrativo colocaria em evidência, ao mesmo tempo, pontos de vista do produtor e classes gramaticais como adjetivos e advérbios; c) aqueles que apresentassem um conflito central ${ }^{5}$ solucionado a partir da visão do autor sobre questões que envolvem a vida do estudante.

Segundo a professora, alguns textos ficaram abaixo de suas expectativas porque apenas descreveram os obstáculos da vida de estudante, sem apresentar qualquer estrutura de narratividade. Outros apresentaram estruturas do tipo linear, em que o cotidiano do estudante era descrito independentemente de qualquer processo de avaliação.

Mas o fato que mais surpreendeu, foi a construção de um texto narrativo, onde o aluno produziu um auto-relato, auto-avaliações e, simultaneamente, avaliações do contexto escolar. A fim de que possamos apreciar melhor a questão, transcrevemos o texto a seguir.

\section{Vida de estudante}

Minha vida como estudante não é muito fácil. Todos os dias acordo de madrugada para ir na escola. Se chego atrazado não tem tolerância e eu tenho que esperar lá fora até bater para o segundo período. Quando faz calor e eu chego atrazado jogo bola com meus colega e ficamos namorando as gurias que ficam do lado de fora só para matar o tempo. Mas quando é frio a gente não aguenta e o porteiro é um chato que não deixa ninguém entrar. Um dia eu cheguei atrasado e pulei a cerca porque tinha prova e o porteiro me entregou e fui parar na sala do careca. O careca me olhou de cara feia e disse que ia chamar a minha mãe porque isso era coisa de guri mau educado. Mau educado são eles que nem se importam que a gente fica no frio.

De acordo com a primeira avaliação realizada, o texto pareceu problemático, pois a solicitação feita, aos alunos, era de que produzissem narrativas em $3^{\mathrm{a}}$ pessoa. $\mathrm{O}$ texto ora estava no presente, ora no pretérito, e continha um excesso de avaliações. Sendo assim, o mesmo acabou tornando-se objeto de estudo coletivo.

${ }^{5}$ Para a elaboração da proposta acima, os professores fundamentaram-se nas discussões de Bastos (1994). 
Questionada a respeito de como costumava avaliar os processos de subjetividade que emergem dos textos, a professora observou que a estranheza talvez estivesse na forma de retratação da realidade, o que lhe causou um impacto. Logo após, questionou-nos a respeito das descontinuidades de tempo e pessoa.

Tais considerações permitiram que refletíssemos, em conjunto a respeito: a) dos imaginários de objetividade/subjetividade construídos com base em leituras de manuais de redação, os quais, via de regra, transferem o espaço da subjetividade ao campo das estruturas; b) das possibilidades de construção de narrativas caracterizadas pela presença de descontinuidades temporais, considerando ainda o fato de que as avaliações poderiam pressupor mudanças de temporalidade.

Por fim, o grupo sugeriu que as práticas de reescrita dos textos fossem realizadas após discussões sobre relações de temporalidade, foco narrativo, presença de conflitos e papel das avaliações, enquanto comentários intercalados e não dominantes no texto narrativo. Através das discussões, portanto, procuramos resgatar as condições de produção dos textos, analisando, a partir das mesmas, a produtividade e o funcionamento das marcas estruturais.

\section{Processo de análise de livros didáticos}

Já na segunda etapa, tomando, em primeiro lugar, livros didáticos cuja apresentação caracterizou-se por defender o pressuposto maior de que a língua é instrumento de comunicação, os alunos da disciplina LET437 passaram a investigar: (a) como tais princípios regulam as práticas pedagógicas propostas pelos livros; (b) de que forma os componentes morfológico, sintático e semântico da língua têm sido articulados e explorados em termos práticos.

A partir de uma primeira investigação, baseada no cotejo entre teoria e prática, foi questionada a consistência da própria concepção dominante de língua, já que todas as práticas formuladas pelos livros em análise concentraram seus esforços em garantir a observação e a correção dos aspectos formais da língua, em detrimento de análises dos processos comunicativos. Em conseqüência, os espaços reservados ao domínio da comunicação apareceram representados por exercícios de sinonímia, antonímia, paráfrase e polissemia, isto é, foram resgatados pelo componente semântico da língua.

Por outro lado, o tratamento dado às questões semânticas caracterizou-se por tomar, como unidades de análise, os vocábulos isolados ou orações, de modo, ainda, a equiparar fenômenos de homonímia e polissemia, sinonímia e paráfrase, ficando as práticas pedagógicas reduzidas a exercícios de reescrita de termos a serem recobertos pelo uso do dicionário.

Em relação às condições de exploração e aproveitamento dos componentes da língua nos exercícios, ficou constatado que o domínio do conteúdo foi preenchido com os componentes mórfico e sintático, os quais foram tratados com abundância de metalinguagem, ao contrário do tratamento proposto às questões de ordem semântica.

Tais fatos, portanto, permitiram-nos colocar em evidência as contradições, inicialmente apontadas, entre teoria e prática, já que, enquanto todas as questões de ordem comunicativa foram homogeneizadas, as questões que privilegiaram tratamentos formais da língua foram explicitadas com farta nomenclatura.

Em uma etapa posterior, tomando como objetos de análise propostas filiadas à Teoria do Texto e a Teorias Genéticas do Conhecimento, os alunos observaram, inicialmente, 
significativas diferenças em termos de propostas teóricas 6 e formas de distribuição de conteúdos. Enquanto as propostas filiadas à primeira corrente apresentam livros, divididos em capítulos, tratando de narração, descrição, argumentação, e abstraem, dessas unidades, práticas de ensino, as propostas filiadas à segunda corrente apresentam livros divididos em unidades temáticas, explorando questões interpretativas, analíticas e estritamente lingüísticas.

Entretanto, ao analisarem relações entre teoria e prática, expressas através dos exercícios que legitimam os domínios teóricos, os alunos observaram nos materiais fundamentados em pressupostos da Teoria do Texto: a) uma unidade específica para evitar a ambigüidade, tratando o processo como uma anomalia a ser evitada na língua; b) uma unidade sobre estrangeirismos, tratando de equivalências semânticas entre formas emprestadas e nativas, e, por fim, aconselhando o leitor a preferir formas nativas, por substituírem perfeitamente as primeiras, independentemente da garantia de produção dos mesmos efeitos de sentido; c) uma unidade sobre conetivos, que trata do funcionamento semântico heterogêneo das conjunções como fatos estilísticos da própria língua.

Já a análise das relações teórico-práticas de propostas sócio-construtivistas demonstrou que, embora a seleção diversificada de temas contribua para expandir o universo de conhecimentos dos alunos, as práticas, envolvendo exploração de aspectos lingüísticos dos textos, remetem a concepções ainda estruturalistas. Deste modo, enquanto as propostas tentam ampliar a noção de texto, saindo da leitura do código para possíveis leituras de mundo, sustentam, por outro lado, uma concepção de que a língua é instrumento de comunicação, transparente, e, conseqüentemente, de que há uma relação simétrica entre mundo, linguagem e sentidos. Portanto, na mesma medida em que concepções interdisciplinares são produzidas, a concepção de língua fica estanque e é reproduzida.

\section{Considerações finais}

\subsection{Interligando saberes: professores e livros didáticos}

Como resultados parciais das etapas até o presente momento desenvolvidas, foram evidenciadas algumas constatações, conforme seguem.

A) A concepção de língua que tem maior credibilidade entre professores e livros didáticos é a mesma: isto é, a língua é vista como instrumento, cuja propriedade mais relevante é a de transparência, e, portanto, serve à comunicação.

B) Há uma correspondência entre o entendimento dos professores e as propostas veiculadas por livros didáticos, quanto aos papéis da nomenclatura na prática de ensino. Na proporção em que exploram os componentes morfológico e sintático da língua, os livros didáticos empregam farta nomenclatura, mas, ao explorarem o componente semântico, suprimem-na, utilizando exercícios de fixação.

C) As discrepâncias entre saturação e ausência de nomenclatura permitem constatar uma lacuna no que se refere à compreensão da heterogeneidade entre campos conceituais $\mathrm{e}$ metalingüísticos.

D) O componente semântico tem sido ainda relegado a último plano devido ao excesso de relevância atribuído ao estudo dos aspectos estruturais da língua e à falta de compreensão do funcionamento do mesmo. Portanto, a gramática ainda resume-se, para muitos, em morfofonética e sintaxe.

\footnotetext{
${ }^{6}$ Referimo-nos aos livros Redação em construção (1993) e Análise, linguagem e pensamento (1993).
} 
E) Os lugares da subjetividade e da intersubjetividade ou são assegurados pelo tratamento das hipóteses internas da língua, ou por práticas pedagógicas, onde o texto continua sendo um meio para se incluírem diferentes dispersões que, marcadamente, atestam as relações desconexas entre os domínios da teoria e o campo da prática.

\section{ANEXOS}

\section{UNIDADE 9}

\section{COMO EVITAR}

A AMBIGÜIDADE?

(3) Uma forma de evitar a ambigüidade semântica é criar uma expectativa de sentido que reduza a possibilidade de dupla significação. Assim, por exemplo, na frase "O rapaz esqueceu a lima na mesa", se, em lugar de rapaz, colocarmos feirante, nenhum leitor entenderá aí o sentido de ferramenta.

Em todas as frases a seguir há ambigüidades. Reduza essa possibilidade, substituindo a palavra em destaque por outra.

1. O freguês esqueceu a carta sobre a mesa.

2. O carregador trouxe a máquina.

3. O homem levou tempo para tirar a mesa.

4. A cliente não conseguiu a linha que desejava.

5. O desconhecido comprou balas perto de sua casa.

(4) Um outro modo de evitar a ambigüidade semântica é a substituição do vocábulo causador da ambigüidade por outro de sentido equivalente e não-polissêmico: sinônimos ou hiperônimos.

Substitua a palavra em destaque nas frases a seguir pelo hiperônimo de um dos seus sentidos.

1. Estava certo de que suas ações iam trazer-lhe benefícios.

2. Discutiam sobre o banco de sua propriedade.

3. Aquilo não era a cadeira da universidade que mais lhe agradava.

4. Encontrou o corredor preparado para a festa.

5. O gráfico veio da rua com a capa na mão. 


\begin{tabular}{|c|c|}
\hline MODO DE & 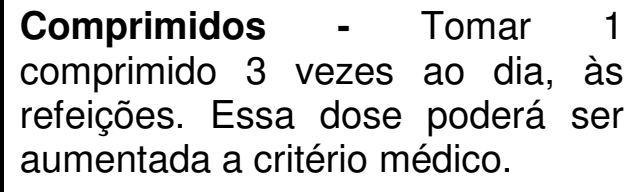 \\
\hline USAR & $\begin{array}{l}\text { Gotas - Crianças Lactentes: } 4 \text { a } 6 \\
\text { gotas, } 3 \text { vezes ao dia. Até } 12 \text { anos: } \\
6 \text { a } 12 \text { gotas, } 3 \text { vezes ao dia. } \\
\text { Acima de } 12 \text { anos: dose igual à do } \\
\text { adulto. Adultos: } 16 \text { gotas, } 3 \text { vezes } \\
\text { ao dia. } \\
\text { As gotas podem ser administradas } \\
\text { diretamente na boca, ou diluídas } \\
\text { num pouco d'água ou outro } \\
\text { alimento. } \\
\text { As doses poderão ser aumentadas } \\
\text { a critério médico. } \\
\text { AGITE ANTES DE USAR. }\end{array}$ \\
\hline
\end{tabular}

Um dos problemas mais comuns que os médicos encontram na prática diária é o das queixas sobre excessos de gases intestinais e a distensão abdominal por eles causada.

Sob a forma de gotas LUFTAL torna-se de valor inconteste no tratamento das cólicas intestinais dos lactentes. Também sob essa forma torna-se fácil a administração aos pacientes acamados no pós-operatório.

Uma dieta leve e o uso de sedativos podem ser de valor como coadjuvante do tratamento.

LUFTAL é fisiologicamente inerte e não apresenta efeitos colaterais, citando-se casos de pacientes que tomaram esse composto por 2 anos e meio sem nenhuma complicação.

\footnotetext{
ATENÇÃO

Siga corretamente o modo de usar: não desaparecendo os sintomas procure orientação médica.

INDICAÇÃO:

Medicação geriátrica e dietética.
} 
MODO DE USAR:

1 cápsula ao dia - USO

ADULTO.

\section{- TODO MEDICAMENTO DEVE SER MANTIDO FORA DO ALCANCE DE CRIANÇAS. \\ - MANTER EM LUGAR SECO E FRESCO. \\ - № LOTE, DATA DE FABRICAÇÃO E VALIDADE, VIDE CARTUCHO.}

\section{BIBLIOGRAFIA}

BASTOS, Lúcia Kopchitz. Coesão e coerência em narrativas escolares. São Paulo, Martins Fontes, 1994.

BRÉAL, Michel. Ensaio de semântica. Campinas, Pontes/EDUC, 1992.

GERALDI, João Wanderley. O professor como leitor do texto do aluno. In: MARTINS, Maria

Helena (org.). Questões de linguagem. São Paulo, Contexto, 1991.

KOCH, Ingedore G. Villaça. Argumentação e linguagem. São Paulo, Cortez, 1984.

PALMER, F.R. A semântica. Lisboa, Edições 70, 1976.

Livros didáticos

BIANCHINI, Orlando; CUNHA, Maria Antonieta. Nos domínios da linguagem; comunicação e expressão e elementos de educação artística ( $5^{\text {a e }} 6^{\text {a }}$ séries). São Paulo, Moderna, 1993.

CARNEIRO, Agostinho D. Redação em construção; a escritura do texto. São Paulo, Moderna, 1993.

CÓCCO, Maria Fernandes; HAILER, Marco Antonio. Análise, línguagem e pensamento; a diversidade de textos numa proposta socioconstrutivista. São Paulo, FTD, 1993.

FERREIRA, Luiz Antonio. Aulas de comunicação em língua portuguesa. São Paulo, Ática, 1984.

MESQUITA, Roberto M. Comunicação e expressão. São Paulo, Saraiva, 1982. 